\title{
Seronegative Erosive Arthritis Following SARS-CoV-2 Infection
}

\author{
Alexandros A. Drosos (1) - Eleftherios Pelechas · Paraskevi V. Voulgari
}

Received: October 6, 2021 / Accepted: October 29, 2021 / Published online: November 16, 2021

(C) The Author(s) 2021

\begin{abstract}
Coronavirus disease 2019 (COVID-19) is caused by the severe acute respiratory syndrome coronavirus 2 (SARS-CoV-2) affecting mostly the respiratory system, but several other organs and systems can be involved. Extrapulmonary manifestations and autoimmune phenomena following SARS-CoV-2 infection are frequent events occurring during the first 2 weeks or in later stages of the disease course. These can be expressed as an isolated discovery of autoantibodies, mostly antinuclear or antiphospholipid antibodies, through to full-blown autoimmune organ-specific and systemic diseases. Joint pain is a frequent complain in most patients, but to our knowledge, frank arthritis has not been reported so far. A 46-year-old woman developed symmetrical polyarthritis 2 months after SARSCoV-2 infection. Laboratory tests showed high acute phase reactants, while the immunological
\end{abstract}

profile was negative. Hand and wrists X-rays revealed soft tissue swelling as well as bone erosions at the ulnar base of the third and fourth metacarpophalangeal joint of the right hand and carpal bones. The patient responded well to small doses of prednisone and methotrexate and after 4 months she had a sustained clinical and laboratory improvement. This is the first report making an association between SARS-CoV-2 infection and erosive polyarthritis. Physicians dealing with patients infected from SARS-CoV-2 should be aware for the possible development of musculoskeletal disorders, among them symmetrical polyarthritis. Thus, a close follow-up and monitoring is mandatory.

Keywords: SARS-CoV-2; Autoimmune phenomena; Symmetrical polyarthritis; Erosive arthritis; Autoantibodies 


\section{Key Summary Points}

Extrapulmonary manifestations after contracting COVID-19 are not uncommon.

Autoimmune phenomena such as autoantibodies and autoimmune diseases are frequently observed in these patients.

Musculoskeletal manifestations are frequent, especially arthralgias and myalgias which are highly recognized in those patients.

Doctors dealing with patients with COVID-19 should be aware of potential flare-ups from the musculoskeletal system of patients with autoimmune rheumatic diseases.

When autoimmune phenomena ensue, a rheumatologist should be implicated in the treatment of those patients.

\section{INTRODUCTION}

Coronavirus disease 2019 (COVID-19) caused by the severe acute respiratory syndrome coronavirus 2 (SARS-CoV-2) is a matter of concern worldwide and a challenge for physicians dealing with patients with autoimmune rheumatic diseases (ARD) [1]. Although the inflammation caused by SARS-CoV-2 infection affects mainly the respiratory system, some patients may develop extrapulmonary manifestations (EPM). These are the result of a hyperinflammatory response of the innate and adaptive immunity, caused by an excessive reaction to the SARSCoV-2 [2, 3]. This exaggerated reaction is characterized by the production and release of a plethora of pro-inflammatory cytokines like interleukin (IL)-1 $\beta$, IL-6, IL-18, tumor necrosis factor alpha (TNF $\alpha)$, and impaired interferon (IFN) type-I response [2-4]. Immune-mediated EPM are frequently recognized in patients with COVID-19 and are associated with various autoimmune phenomena $[5,6]$. The clinical features range from the detection of an autoantibody, mainly antinuclear antibodies (ANA) or antiphospholipid antibodies (APLs), to a mild and benign disease, but there are cases that lead to full-blown organ-specific and systemic autoimmune diseases like thyroiditis, myositis, myocarditis, vasculitis, peripheral neuropathy, antiphospholipid syndrome (APS), and many others [7, 8]. Arthralgias and joint pain have been reported in about $40 \%$ of patients contracting COVID-19. However, frank arthritis with evidence of inflammation upon physical examination of the involved joints, to our knowledge, has not been reported so far. To this end, we report a 46-year-old woman who developed symmetrical polyarthritis affecting the small joints of the hands, 2 months after SARS-CoV-2 infection. Laboratory evaluation revealed high acute phase reactants without specific autoantibodies, while imaging modalities showed erosive changes affecting the third and fourth metacarpophalangeal (MCP) joints of the right hand and carpal bones. The relevant literature was searched and discussed.

A written informed consent has been obtained and signed by the patient. All procedures were in accordance with ethical standards and the Helsinki Declaration of 1964 and its later amendments. Ethics committee approval by our institution is not required if manuscripts do not show details of the presented patients.

\section{CASE PRESENTATION}

A 46-year-old woman presented on May 4, 2021 with pain and swelling affecting the small joints of the hands bilaterally, lasting for 6 weeks. She received paracetamol and non-steroidal antiinflammatory drugs [(NSAIDs), diclophenac $75 \mathrm{mg}$ bid], without significant improvement. She was a single, non-smoker with negative past medical and family history. However, on February 1, 2021 she had been diagnosed with SARS-CoV-2 infection, based on low grade fever, sore throat, myalgias, arthralgias, and a positive polymerase chain reaction (PCR) for COVID-19. She remained isolated at home, receiving occasionally paracetamol, and 3 weeks later she was 


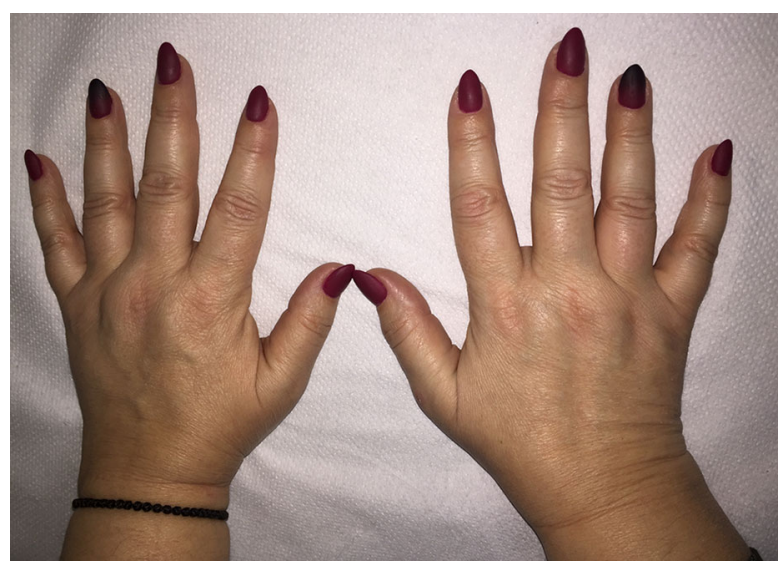

Fig. 1 Symmetrical swelling of the MCP and PIP joints bilaterally. MCP metacarpophalangeal joints, PIP proximal interphalangeal joints

free of symptoms. A new test for SARS-CoV-2 infection was negative. However, 1 month later she complained for arthralgias, morning stiffness, and swelling of the small joints of the hands. She repeated a new SARS-CoV-2 test which was negative.

Clinical examination revealed swelling and tenderness affecting the MCPs and proximal interphalangeal (PIP) joints bilaterally (Fig. 1). She denied photosensitivity, skin rashes, psoriasis, oral ulcers, Raynaud's phenomenon, uveitis, urethritis, and diarrhea. Laboratory tests showed high C-reactive protein (CRP) [60 mg/dl (normal values $<6$ )], high erythrocyte sedimentation rate [(ESR) $82 \mathrm{~mm} / \mathrm{h}$ ], and high IgG antibodies against SARS-CoV-2, while a new PCR test was negative. The rest of the laboratory tests including ANA, rheumatoid factor (RF), and anti-citrullinated protein antibodies (ACPA) were all negative. Chest X-rays were negative, while hand X-rays showed soft tissue swelling and erosions affecting the ulnar base of the 3rd and 4th MCP of the right hand and carpal bones, as well as joint space narrowing of the 2nd and 3rd MCPs and radiocarpal joint bilaterally (Fig. 2a). The aforementioned findings were better visualized with the use of musculoskeletal ultrasonography, which detected an erosive lesion involving the base of the 4th MCP of the right hand measuring $8 \mathrm{~mm}$ of diameter (Fig. 2b). On the basis of the American College of Rheumatology (ACR) classification
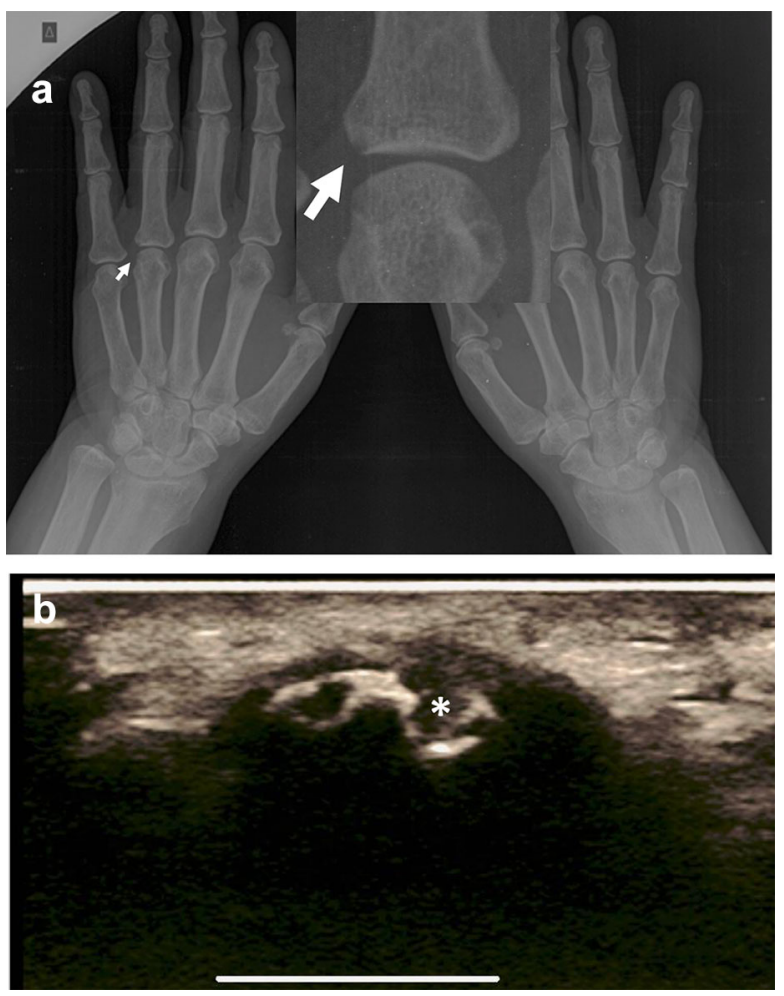

Fig. 2 a Hand and wrists radiographs showing soft tissue swelling around the PIP joints bilaterally, and an erosive change is evident on the proximal ulnar side of the proximal phalanx of the 4th digit of the right hand (arrow). Note also joint space narrowing of the 2 nd and 3rd MCPs and of the radiocarpal joint bilaterally. MCP metacarpophalangeal joints, PIP proximal interphalangeal joints. b Musculoskeletal ultrasound in B-mode. An erosive lesion is evident on the ulnar base of the 4th digit of the right hand (white asterisk) Note also that another erosion is forming more distally

criteria, 1987 and 2010, she was classified as having seronegative rheumatoid arthritis (RA) $[9,10]$.

She was treated with methotrexate (MTX), $15 \mathrm{mg} /$ week and folic acid supplements, plus prednisone $10 \mathrm{mg} /$ day. Two months later she had a substantial clinical improvement with normal acute phase reactants; thus, prednisone was tapered. After 4 months the patient had a complete clinical and laboratory improvement receiving MTX $15 \mathrm{mg} /$ day and prednisone $2.5 \mathrm{mg} /$ day. 


\section{DISCUSSION}

COVID-19, caused by SARS-CoV-2 infection, can lead to severe inflammation and has also been suggested to induce EPM and autoimmune phenomena $[7,8]$. Several studies have reported the presence of autoantibodies in patients with COVID- 19 , mostly ANAs, APLs, and anti- $\beta 2$ glycoprotein I antibodies [11-14]. ACPAs and RF in low titers have also been described, but frank arthritis with structural damage has not been reported so far. In this report we describe, for the first time, the onset of seronegative erosive RA in a patient after COVID-19.

Autoimmune phenomena related to COVID19 were initially described in severe hospitalized patients, but have been also reported in patients with mild COVID-19 and even in asymptomatic patients. The severity of the autoimmune manifestations of COVID-19 varies, ranging from a benign and self-limiting disease like psoriasis to systemic lupus erythematosus (SLE), or APS and vasculitis [7, 8]. Some autoimmune phenomena in relation to COVID-19 tend to occur during the first 2 weeks, whereas others tend to manifest in a late, post-infectious stage, and also in asymptomatic patients.

Little is known about the pathogenesis of these manifestations, since autoantibodies are absent in many cases, as in our patient. One hypothesis has reported the presence of autoantibodies against IFN type I, or inborn errors in type I IFN immunity $[15,16]$. Another hypothesis implies that SARS-CoV-2 infection can disturb immunological tolerance by exposure of antigen epitopes that elicit cross-reactive antibodies. There are several reports indicating antigenic mimicry between viral and human proteins.

One published example of molecular mimicry is the immune response of Epstein-Barr virus (EBV) in patients with SLE $[17,18]$. On the other hand, the etiology of RA is multifactorial. Genetic factors, among them the human leucocyte antigen (HLA) DRB1 shared epitope (SE), hormonal factors, and environmental exposure such as smoking, or infectious agents, may predispose to RA development. The SE hypothesis implies that susceptibility alleles could bind efficiently to arthritogenic peptides (self-antigen or viral peptide), leading to activation of $\mathrm{CD}^{+}{ }^{+} \mathrm{T}$ cells and production of antibodies, like RF and ACPAs, through B cell activation [19]. Several viruses have been postulated as possible etiologic factors in RA, among them EBV, parvovirus B-19 and many others. For example, EBV is a polyclonal activator of $B$ cells and increases the production of RF. Another hypothesis implies that the EBV gp110 protein is one of the many xenoproteins found in SE. Such proteins might trigger responses through the molecule mimicry hypothesis, leading the immune response directed against a similar endogenous protein. Indeed, Gammazza et al. compared viral proteins with human molecular chaperones and postulated that chaperones could participate in molecular mimicry phenomena after SARS-CoV-2 infection [20]. Several other studies suggested molecular mimicry as a possible mechanism underlying the development of autoimmune phenomena in SARSCoV-2 infection [21-23]. However, the possibility of other types of seronegative arthritides should be excluded. Reactive arthritis (ReA) is one of them. Usually, ReA is manifested as a mono- or oligoarticular disease affecting mostly the large joints of the body, following a gastrointestinal or genitourinary infection [24]. In the discussed case, our patient presented with symmetrical polyarthritis affecting the small joints of the hands and had no history of urethritis or gastrointestinal infection. Another possibility is the coincidence of seronegative RA with COVID-19 disease, or the presence of RA and its flaring after SARS-CoV-2 infection [14]. This possibility is difficult to exclude; however, our patient had no history of arthralgias, or signs and symptoms of arthritis before SARSCoV-2 infection. Finally, the presence of erosive disease in this case and its chronological relationship with COVID-19 disease is a matter of discussion, since structural damage in RA is manifested late during the disease course. On the other hand, erosive changes can also be seen in patients with early RA and this finding can be assumed as an unfavorable prognostic factor for RA outcome [25]. Treatment-wise, these autoimmune phenomena can be combated depending on the clinical features and their 
severity. In cases of systemic manifestations, small to high doses of steroids with or without immunosuppressive drugs are required. In mild cases, close follow-up and monitoring may be sufficient. In our patient, small doses of prednisone along with MTX were sufficient to suppress the inflammatory process. We searched Medline and Scopus sources using the following keywords and found no other cases published so far: SARS-CoV-2 and erosive symmetrical polyarthritis or/and COVID-19 and symmetrical erosive disease.

In conclusion, we described a patient with seronegative erosive RA following SARS-CoV-2 infection. Early recognition of the specific types of autoimmune phenomena and diseases after COVID-19 is an imperative for physicians and will allow them to have an accurate diagnosis and treatment. Thus, close follow-up and monitoring is mandatory.

\section{ACKNOWLEDGEMENTS}

We thank Ms Areti Fili for her excellent secretarial assistance.

Funding. No funding or sponsorship was received for this study or publication of this article.

Authorship. All named authors meet the International Committee of Medical Journal Editors (ICMJE) criteria for authorship for this article, take responsibility for the integrity of the work as a whole, and have given their approval for this version to be published.

Author Contributions. Alexandros A. Drosos: concept and design, critical review. Eleftherios Pelechas: drafting the manuscript, bibliographic evaluation. Paraskevi V. Voulgari: critical review, drafting.

Disclosures. Alexandros A. Drosos, Eleftherios Pelechas, and Paraskevi V. Voulgari have nothing to disclose.

Compliance with Ethics Guidelines. All procedures were in accordance with ethical standards and the Helsinki Declaration of 1964 and its later amendments. Ethics committee approval by our institution is not required if manuscripts do not show details of the presented patients.

Data Availability. Data sharing is not applicable to this article as no datasets were generated or analyzed during the current study.

Open Access. This article is licensed under a Creative Commons Attribution-NonCommercial 4.0 International License, which permits any non-commercial use, sharing, adaptation, distribution and reproduction in any medium or format, as long as you give appropriate credit to the original author(s) and the source, provide a link to the Creative Commons licence, and indicate if changes were made. The images or other third party material in this article are included in the article's Creative Commons licence, unless indicated otherwise in a credit line to the material. If material is not included in the article's Creative Commons licence and your intended use is not permitted by statutory regulation or exceeds the permitted use, you will need to obtain permission directly from the copyright holder. To view a copy of this licence, visit http:// creativecommons.org/licenses/by-nc/4.0/.

\section{REFERENCES}

1. Gianfrancesco $\mathrm{M}$, Hyrich KL, Al-Adely $\mathrm{S}$, et al. Characteristics associated with hospitalization for COVID-19 in people with rheumatic disease: data from the COVID-19 Global Rheumatology Alliance physician-reported registry. Ann Rheum Dis. 2020;79(7):859-66. https://doi.org/10.1136/ annrheumdis-2020-217871.

2. Wiersinga WJ, Rhodes A, Cheng AC, Peacock SJ, Prescott HC. Pathophysiology, transmission, diagnosis, and treatment of coronavirus disease 2019 (COVID-19): a review. JAMA. 2020;324(8):782-93. https://doi.org/10.1001/jama.2020.12839.

3. Connors JM, Levy JH. COVID-19 and its implications for thrombosis and anticoagulation. Blood. 2020;135(23):2033-40. https://doi.org/10.1182/ blood.20200060000. 
4. Hadjadj J, Yatim N, Barnabei L, et al. Impaired type I interferon activity and inflammatory responses in severe COVID-19 patients. Science. 2020;369(6504):718-24. https://doi.org/10.1126/ science.abc6027.

5. Gupta A, Madhavan MV, Sehgal K, et al. Extrapulmonary manifestations of COVID-19. Nat Med. 2020;26(7):1017-32. https://doi.org/10.1038/ s41591-020-0968-3.

6. Rouse BT, Sehrawat S. Immunity and immunopathology to viruses: what decides the outcome? Nat Rev Immunol. 2010;10(7):514-26. https://doi.org/10.1038/nri2802.

7. Ramos-Casals M, Brito-Zerón P, Mariette X. Systemic and organ-specific immune-related manifestations of COVID-19. Nat Rev Rheumatol. 2021;17(6):315-32. https://doi.org/10.1038/ s41584-021-00608-z.

8. Liu Y, Sawalha AH, Lu Q. COVID-19 and autoimmune diseases. Curr Opin Rheumatol. 2021;33(2): 155-62. https://doi.org/10.1097/BOR. 0000000000000776.

9. Arnett FC, Edworthy SM, Bloch DA, et al. The American Rheumatism Association 1987 revised criteria for the classification of rheumatoid arthritis. Arthritis Rheumatol. 1988;31(3):315-24. https:// doi.org/10.1002/art.1780310302.

10. Aletaha D, Neogi T, Silman AJ, et al. 2010 Rheumatoid arthritis classification criteria: an American College of Rheumatology/European League Against Rheumatism collaborative initiative. Arthritis Rheumatol. 2010;62(9):2569-81. https:// doi.org/10.1002/art.27584.

11. Vlachoyiannopoulos PG, Magira E, Alexopoulos H, et al. Autoantibodies related to systemic autoimmune rheumatic diseases in severely ill patients with COVID-19. Ann Rheum Dis. 2020;79(12): 1661-3. https://doi.org/10.1136/annrheumdis2020-218009.

12. Borghi MO, Beltagy A, Garrafa E, et al. Anti-phospholipid antibodies in COVID-19 are different from those detectable in the anti-phospholipid syndrome. Front Immunol. 2020;11: 584241. https:// doi.org/10.3389/fimmun.2020.584241.

13. Perrot L, Hemon M, Busnel JM, et al. First flare of ACPA-positive rheumatoid arthritis after SARS-CoV2 infection. Lancet Rheumatol. 2021;3(1):e6-8. https://doi.org/10.1016/S2665-9913(20)30396-9.

14. Derksen VFAM, Kissel T, Lamers-Karnebeek FBG, et al. Onset of rheumatoid arthritis after COVID-19: coincidence or connected? Ann Rheum Dis. 2021. https://doi.org/10.1136/annrheumdis-2021219859.

15. Bastard P, Rosen LB, Zhang Q, et al. Autoantibodies against type I IFNs in patients with life-threatening COVID-19. Science. 2020;370(6515): eabd4585. https://doi.org/10.1126/science.abd4585.

16. Zhang Q, Bastard P, Liu Z, et al. Inborn errors of type I IFN immunity in patients with life-threatening COVID-19. Science. 2020;370(6515): eabd4570. https://doi.org/10.1126/science.abd4570.

17. Harley JB, James JA. Everyone comes from somewhere: systemic lupus erythematosus and Epstein-Barr virus induction of host interferon and humoral anti-Epstein-Barr nuclear antigen 1 immunity. Arthritis Rheumatol. 2010;62(6): 1571-5. https://doi.org/10.1002/art.27421.

18. Jog NR, Young KA, Munroe ME, et al. Association of Epstein-Barr virus serological reactivation with transitioning to systemic lupus erythematosus in at-risk individuals. Ann Rheum Dis. 2019;78(9): 1235-41. https://doi.org/10.1136/annrheumdis2019-215361.

19. Gregersen PK, Silver J, Winchester RJ. The shared epitope hypothesis. An approach to understanding the molecular genetics of susceptibility to rheumatoid arthritis. Arthritis Rheumatol. 1987;30(11): 1205-13. https://doi.org/10.1002/art.1780301102.

20. Gammazza AM, Légaré S, Bosco GL, et al. Human molecular chaperones share with SARS-CoV-2 antigenic epitopes potentially capable of eliciting autoimmunity against endothelial cells: possible role of molecular mimicry in COVID-19. Cell Stress Chaperones. 2020;25(5):737-41. https://doi.org/10. 1007/s12192-020-01148-3.

21. Lucchese G, Flöel A. SARS-CoV-2 and Guillain-Barré syndrome: molecular mimicry with human heat shock proteins as potential pathogenic mechanism. Cell Stress Chaperones. 2020;25(5): 731-5. https://doi.org/10.1007/s12192-020-011456.

22. Lucchese G, Flöel A. Molecular mimicry between SARS-CoV-2 and respiratory pacemaker neurons. Autoimmun Rev. 2020;19: 102556. https://doi.org/ 10.1016/j.autrev.2020.102556.

23. Venkatakrishnan AJ, Kayal N, Anand P, Badley AD, Church GM, Soundararajan V. Benchmarking evolutionary tinkering underlying human-viral molecular mimicry shows multiple host pulmonary-arterial peptides mimicked by SARS-CoV-2. Cell Death Discov. 2020;6:96. https://doi.org/10. 1038/s41420-020-00321-y. 
24. Selmi C, Gershwin ME. Diagnosis and classification of reactive arthritis. Autoimmun Rev. 2014;13(4-5): 546-9. https://doi.org/10.1016/j.autrev.2014.01. 005.
25. Drosos AA, Pelechas E, Voulgari PV. Conventional radiography of the hands and wrists in rheumatoid arthritis. What a rheumatologist should know and how to interpret the radiological findings. Rheumatol Int. 2019;39(8):1331-41. 